\title{
Interactivity: A review of the concept and a framework for analysis
}

\author{
OLIVER QUIRING and WOLFGANG SCHWEIGER
}

\section{Abstract}

The terms 'interactivity' and 'interactive media' became significant buzzwords during the late 1980s and early 1990s when the multi-media euphoria fascinated politicians, economists, and researchers alike. However, right from the beginning of the scientific debate, the inconsistent usage of the term 'interactivity' massively complicated the comparability of numerous empirical studies. This is where this article joins the discussion. First, the article sheds light on the terminological origins of 'interactivity' and distinguishes the term from cognate expressions. Further, it restructures and extends existing findings on the basis of a new analysis framework which considers three levels of interactive communication (action level, level of subjective situation evaluation, and level of meaning exchange). Finally, it delivers a systematic overview of specific criteria of interactive communication.

Keywords: interactivity, framework, computer-mediated-communication, human-machine interaction, Internet, media use

\section{Introduction}

'Interactivity' and 'interactive media' became significant buzzwords during the late 1980s and early 1990s when the multi-media euphoria fascinated politicians, economists, and researchers alike. During the last decade this multimedia euphoria of the early days slowed down distinctly although new technologies were developed continuously. The term 'interactive' was used less frequently but constantly within communication science publications.

The term as well as the idea of 'interactivity' has, despite some pioneer articles (e.g., Durlak, 1987; Rafaeli, 1988; Heeter, 1989; Steuer, 1992), not been explained satisfactorily so far. Schönhagen (2004: 19) recently 
referred to interactivity as an open term. Typing the term 'interactivity' into Google results in over 8,780,000 hits (1 December 2006). Reviewing these hits one will soon recognize that the respective authors give a great variety of definitions. They also treat different aspects of interactive communication. Even when they share one perspective, their concepts are often contradictory. Until the mid 1990s 'interactivity' was regarded primarily as a (technological) attribute of new media. Researchers thereafter started to take a closer look at the role of the user (Höflich, 1995: 519; McMillan, 2000). Therefore, a broader, more extensive concept seems necessary to describe interactivity and interactive communication adequately. In this article, we will make an attempt to reconstruct the origins of the term and to distinguish it from related terms such as 'interaction'. We will lay out a framework of analysis that distinguishes three levels of interactive communication: The level of (observable) action, the level of subjective evaluation of the situation by the user, and the level of the exchange of meaning. Finally, we will systemize and discuss the central characteristics of interactivity dealt with in existing literature with the help of this framework.

\section{Understanding the Term 'Interactivity'}

When examining the origins of the term 'interactivity', two scientific disciplines are paramount: sociology and computer sciences. Communication science started to deal with the term in the late 1980s when new computer technologies became relevant for the distribution and re-conception of mass media content (e. g., Heeter, 1989).

\section{Interaction}

The origin of the term 'interactivity' is closely related to the term 'interaction', which plays a central role in the context of sociological action theory. Here, interaction means human actions aimed at each other, thus the relations between two or more human beings (Blumer, 1986). The central aspect of interaction is the mutual orientation and perception of interacting partners (Jäckel, 1995). According to symbolic interactionism, which deals explicitly with interpersonal communication, people communicate on the basis of symbols and meanings which therefore emerge within the communication process and are subject to historical changes (Blumer, 1986; Mead, 1934). Originally, this definition applies to face-to-face communication, which might be of verbal, para-verbal, or non-verbal nature. Interaction thereby takes place within so-called 'reaction sequences'; sequences where actions of one person result in reactions of another person. Since such interactions may occur via tech- 
nical means of communication such as telephone or networked computers, the physical presence of interaction partners no longer seems to be an essential criterion (Jäckel, 1995: 467).

Computer sciences adopted the term and transferred it to the use of computer systems by human beings. Human-Computer-Interaction (HCI) as a field of research examines the structure of user interfaces in order to improve and facilitate the dialogue between man and machine (Biocca, 1993; McMillan, 2002a). The main research objective of HCI is the usability of hardware and software (e.g. Nielsen, 2000; Lowe and Hall, 1999; Forsythe, Grose, and Ratner, 1998). The initial point of HCI research was a technical achievement: Until the 1980s, mainframe computers connected to workstations dominated the professional computer sector. The user fed these large-capacity computers with extensive calculations, which were implemented via batch processing and whose results were forwarded to the workstations. It is obvious that batch processing was hardly user-friendly as solely computer professionals were able to master it. Later, when cheap and more powerful personal computers were introduced, users were able to handle more and more tasks themselves. When personal computers finally entered private households, the improvement and facilitation of the man-machine dialogue became central because the users often only had marginal technical skills.

Even though both fields, sociology and computer sciences, use the term 'interaction', two different circumstances are considered. In a sociological sense, 'interaction' refers to interpersonal communication, no matter whether through face-to-face or through technical means. In contrast, computer sciences use the term 'interaction' in the context of manmachine communication. Interpersonal communication via computer may be considered as an overlap between both research fields. Pure manmachine dialogue as examined from the HCI point of view is not considered communication from the social perspective. Vice versa, direct interpersonal communication is not of interest for computer sciences.

Communication science focusing on mass media therefore links both perspectives. Initially, media use and effects research concentrated on the contact of people with mass media, thinking of recipients as an 'active audience'. The uses- and gratifications approach in particular, examining the use of mass media by recipients according to their needs (e. g., Katz, Blumler, and Gurevitch, 1973; Rubin, 2002), comes close to the perspective of computer sciences as it analyzes interaction between recipients and technical media and its contents respectively. However, as media supply and content are always produced by human communicators trying to obtain other humans as their audience, the communicational perspective implicitly considers communication between human beings. While the sociological understanding of 'interaction' always implies two- 
way communication, mass communication takes place one-sided from the communicator via technical devices to the recipient (Maletzke, 1963: 32). That may be one reason why the concept of interaction rarely occurs in communication science debates.

Therefore, communication science rather focuses on man-media communication, but with an implicit sociological understanding of communication. Subsequently, we will discuss how to combine both perspectives and how to show its heuristic potential with the help a new framework of analysis.

While media use research examines the individual selection and reception process, recipient feedback directed from the audience to the communicator has rarely been subject of empirical studies. Few studies dealt with the issue of feedback channels of traditional media. Bierig and Dimmick (1979) and Orians (1991), for example, examined records of listeners calling into radio stations. Davies and Rarick (1964), Forsythe (1950), and Grey and Brown (1970) examined letters to editors. Gans (1977) and McGuire and Leroy (1977) finally researched letters to TVeditors. Moreover, one can find more common examples for interaction in mass media communication, such as lotteries in print media, radio, or TV where recipients communicate via postcards. Interactions by phone are not unusual either; just think of tele-voting, music request programs, game shows, and tele-shopping.

\section{From interaction to interactivity}

Traditional media therefore allow interactions in a sociological sense. Nevertheless, it is predominantly argued that the interactivity concept is limited to computer-based communication. As a matter of fact, at least four differences between traditional interactions and interactive onlinemedia can be observed.

First of all, when using online media feedback facilities users do not have to change the device they are currently using. While feedback on TV-shows for example is carried out via postcard, telephone, SMS or email, website visitors are able to communicate via contact forms or email. Secondly, computer-based services such as email, chat, or discussion forums allow the audience to contact communicators quickly, easily, and often free of charge. Thirdly, media suppliers are also able to respond to feedback quickly and, where appropriate, incorporate it into their systems. Discussion forums or user ballots on websites of daily newspapers may be cited as an example. Additionally, media data such as visits per day or page impressions are collected easily, free of charge, and non-reactive (i.e. without being noted by the user). Fourthly, even in the mass media sector, boundaries between communicators and recipi- 
ents become increasingly blurred, especially when users act as authors (see Schweiger and Quiring, 2005). To this point, the online encyclopedia Wikipedia may serve as one of the most prominent examples for usergenerated content. To which extent the convergence of end-devices may actually progress and thus enter the field of traditional media is not yet clear. Nevertheless, some critical voices on convergence (King, 1998; Schönbach, 1997) may already be seen as disproved, especially because current studies indeed observe a relevant convergence of end-devices (Woldt, 2004).

However, the question whether the meaning of 'interactivity' is the same as of 'interaction' is still open. It makes it even harder to distinguish the two terms as 'interactivity' is used partly synonymously with 'interaction' and partly to differentiate between social communication and man-machine-dialogue. At least three criteria can act as indicators for distinguishing the terms 'interaction' and 'interactivity'. First, 'interactivity' claims for real and observable interactions among humans via a machine or between man and machine, and thus implies real human behavior. Intra-personal processes, as described for example within the phenomenon of para-social interaction (e.g., Horton and Wohl, 1956; Rubin and Step, 2000), insufficiently constitute interactivity. Second, in case of interactivity a technical component occupies a key position within the communication process (Carey, 1989; Brody, 1990). Third, no change of devices will be necessary for interactive communication.

\section{A framework of analysis for interactivity}

However, it is still not evident what 'interactivity' is all about. To give consideration to existing, heterogeneous perspectives (e.g. interactivity as criterion of technical systems, processes, users, see section 3) we suggest conceiving interactivity solely as a process of inter-human communication via technical means. Different levels of analysis will be separated in the next step.

We distinguish the exchange of meaning on the one hand and the observable behavior towards other people or systems on the other hand, which will be called 'action' hereafter.

According to our understanding, the exchange of meaning solely occurs between human beings. An exchange of meaning between man and machine is impossible.

Actions occur whenever humans consciously interact with other humans or media systems. Examples of interpersonal constellations are: Conversation, facial expressions, gesture, and body encounters. Typical actions in the context of media use are: Selection and control via mouse click, browsing/scrolling, navigating via keyboard, mouse, joystick or 
steering wheel, text input or voice entry, but also reading of online contents or using of multimedia applications. Interactive media systems are reacting on the user's actions, displaying search results, transferring emails or displaying new challenges in our favorite computer game.

Three scenarios result from this differentiation:

1. When dealing with face-to-face communication, the exchange of meaning and actions usually coincide. You interact with whom you exchange meaning, no matter whether you communicate with one person or more. As the condition of a technical media is not fulfilled in this case, face-to-face communication does not fulfill a crucial criterion for 'interactivity'.

2. When two or more people communicate via technical systems, the exchange of meaning and actions fall apart because communication partners refer meaning to each other but interact with the technical system as a means of communication (Goertz, 1995). In such a communication scenario all conditions for interactivity are fulfilled. We call this type of interactivity user-user interactivity. The most common example for user-user interactivity is email. Instant messengers (a modern variation of chat-rooms) allow an even higher exchange rate of messages. User-user-interactivity is not necessarily limited to two users ('one-to-one' communication), but may allow numerous users to communicate ('one-to-many' or 'many-to-many' communication; for example mailing lists, newsgroups, or online forums).

3 . The term user-system interactivity describes a communication scenario where humans interact with a media system, which presents content and may react on input by the user (McMillan, 2002a), but does not allow real communication due to the fact that it is not capable of actively constructing meaning. In contrast to Goertz (1995) we do not apprehend the system as a communication partner, but as a reference object for the user's action. However, interpersonal communication indeed provides a basis for the improvement of such systems and their contents. Imitation of interpersonal communication is one of the main aims of developers of interactive media and software (Durlak, 1987). For decades, artificial intelligence research has been paying tribute to the ideal of the mathematician Alan Turing (Turing, 1950), whose aim was to develop a computer system capable of communicating humanly with human beings.

Since a (technical) media system is not capable of exchanging meanings, does user-system interactivity completely exclude the transmission of meaning? The answer is no. Every media system and its contents were originally developed and will continue to be enhanced by human beings. 
Two significant roles have to be distinguished in this context; technical developers and content developers.

Developers of content are people who professionally deal with the production of media content. We think of traditional communicators such as journalists, producers, PR consultants, or politicians etc. Technical developers are engaged in hardware and software construction and improvement. They generate algorithms, according to which interactive systems combine content and thus react on the user's individual input. The more extensive and complex these rules and contents, the more the user will get the impression of a natural communication situation. Nevertheless, it is still human beings who transfer meaning to systems. Weber (1984: 22) already refers to the fact that "every artifact, for example a machine (...) can only be understood by the meaning that human action (...) conferred to this artifact during its production and use". The term 'action' describes the developer's actual work on a media system. The meaning thereby implanted is an indispensable requirement for the subsequent exchange of meaning. Meaning exchange in user-system interactivity therefore always takes place between users and developers of media systems. As observed in mass media communication, most of the time a one-sided transfer of meaning takes place. Even though there are some feedback channels, ranging from email to the active production of user generated content (e. g., skinning and mapping in computer games which is often done by devoted users).

Let us summarize our findings so far: interactivity of technical media systems always implies the differentiation between action and the exchange of meaning. There are two forms of interactivity; it is a matter of user-system interactivity when we find user and developer communicating, and it is a matter of user-user interactivity when users communicate with each other. To be more precise, even in user-user interactivity communication additionally takes place between the developers and the users because developers create communicational rules and standards, which have to be obeyed by all users. If providers of online dating services, for example, do not admit clients' photos on their website to keep their service free from superficialities, they also (a) transfer a certain value and (b) have an effect on their users' communication facilities.

To what extent and how meaning is actually transferred not only depends on the objective features of the system but also on the individual evaluation of the situation by users and developers. By 'evaluation of the situation' we understand the subjective perception of both the interactive system and the communication situation. The evaluation of the situation has a vital impact on observable behavior (actions) and the exchange of meaning. While the system characteristics may limit possible actions and 


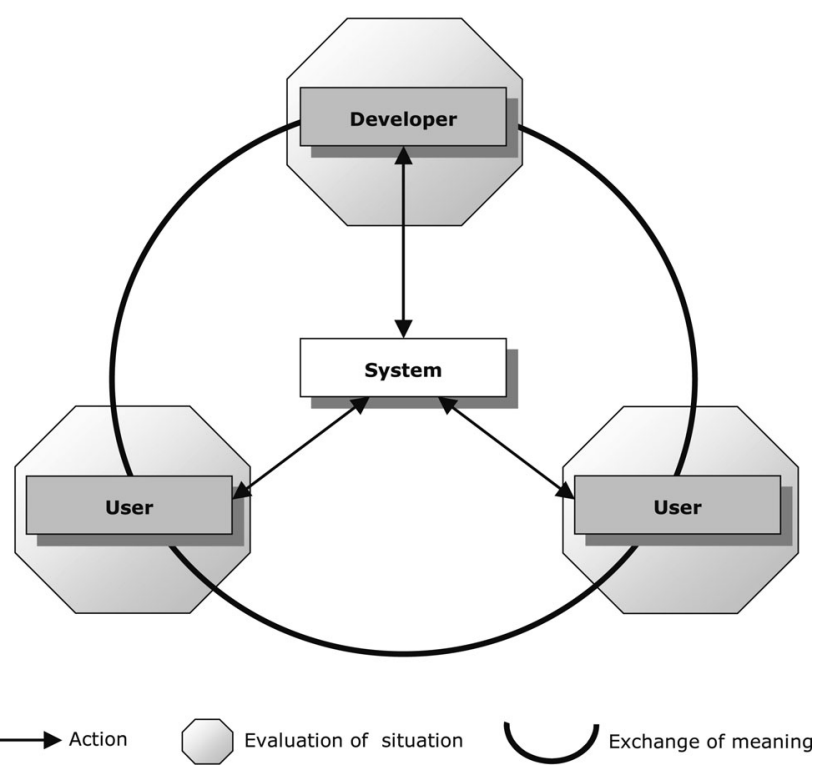

Figure 1. Action, evaluation of the situation and exchange of meaning in interactive settings.

therefore transferable meaning, the evaluation of the situation has an impact on the context specific, individual actions and therefore the real extent of meaning transfer. Some examples may help to make this point clear: most e-mail clients enable the insertion of photographs etc. within the text. Whether this function is actually used depends on the technical conditions and the user's knowledge about it. Whether intimate content is sent by email or not should for example depend on the perceived associated risk to display such contents to strangers. The evaluation of the situation by a player of a multi-player online game may serve as an example as well. A detailed presentation of the three different levels of interactivity (action, evaluation of the situation, and exchange of meaning) and their specific dimensions and characteristics will follow in section 3. Figure 1 illustrates the analysis framework as described.

\section{Levels, dimensions, and characteristics of interactivity}

The heuristic value of the analysis framework described can be estimated amongst others by its appropriateness to systematize, link and extend familiar definitions, characteristics and concepts. Though interactivity results, as described before, from the complex co-action of (a) system 
Table 1. Levels, Dimensions and Characteristics of Interactivity.

\begin{tabular}{|c|c|c|c|}
\hline \multicolumn{2}{|l|}{ Level } & \multirow{2}{*}{$\begin{array}{l}\text { Dimension } \\
\text { Control }\end{array}$} & \multirow{2}{*}{$\begin{array}{l}\text { Characteristics } \\
\text { - selection } \\
\text { - modification }\end{array}$} \\
\hline Action & User & & \\
\hline & & Transfer & $\begin{array}{l}\text { - sensory activation (aural, tactilely, } \\
\text { olfactory, gustatory, visual) }\end{array}$ \\
\hline & System & Control & $\begin{array}{l}\text { - selection options (range, speed, timing } \\
\text { flexibility) } \\
\text { - modification options (range, speed, } \\
\text { timing flexibility) } \\
\text { - transformation rules (algorithms) }\end{array}$ \\
\hline & & Transfer & $\begin{array}{l}\text { - sensory complexity (aural, tactilely, } \\
\text { olfactory, gustatory, visual) }\end{array}$ \\
\hline \multirow{2}{*}{\multicolumn{2}{|c|}{$\begin{array}{l}\text { Evaluation of } \\
\text { the situation }\end{array}$}} & $\begin{array}{l}\text { System } \\
\text { evaluation }\end{array}$ & $\begin{array}{l}\text { - evaluation of controls: } \\
\text { selection options (range, speed, timing } \\
\text { flexibility) } \\
\text { modification options (range, speed, } \\
\text { timing flexibility) } \\
\text { transformation rules } \\
\text { - evaluation of the sensory complexity } \\
\text { (transfer) }\end{array}$ \\
\hline & & $\begin{array}{l}\text { Situational } \\
\text { sensations }\end{array}$ & $\begin{array}{l}\text { - } \text { playfulness } \\
\text { - connectedness } \\
\text { - sense of place/presence } \\
\text { - immersion }\end{array}$ \\
\hline \multirow[t]{3}{*}{$\begin{array}{l}\text { Exchange of } \\
\text { meaning }\end{array}$} & & $\begin{array}{l}\text { Encoding of } \\
\text { meaning }\end{array}$ & $\begin{array}{l}\text { - evaluation of addressees and their } \\
\text { expectations } \\
\text { - interrelatedness of messages } \\
\text { - intent of communication }\end{array}$ \\
\hline & & $\begin{array}{l}\text { Disposition of } \\
\text { power }\end{array}$ & $\begin{array}{l}\text { - control } \\
\text { - direction of communication }\end{array}$ \\
\hline & & $\begin{array}{l}\text { Decoding of } \\
\text { meaning }\end{array}$ & $\begin{array}{l}\text { - evaluation of senders and their intentions } \\
\text { - interrelatedness of messages } \\
\text { - individual processing and interpretation } \\
\text { of information }\end{array}$ \\
\hline
\end{tabular}

characteristics, (b) the users' evaluation of the situation, (c) actions of the users and the system's reaction, and (d) the transferred meaning, previously released definitions cover either only parts of the whole framework or, in the case of multi-dimensional concepts (cp., e.g., Heeter, 1989; Goertz, 1995; Jensen, 1998; McMillan, 2002a) , insufficiently explain the different dimensions. To cover all meanings of 'inter- 
activity' transported in the literature so far, we examined existing definitions and concepts regarding to their core elements and adapted them to our framework of analysis. It has to be noted that this overview can by no means be exhaustive due to the term's inflationary usage. We have therefore solely taken concepts into consideration that explicitly define and conceive 'interactivity'. Table 1 introduces the essential dimensions and characteristics of interactivity by the three levels of action, evaluation of the situation, and exchange of meaning as discussed in the preceding sections. To simplify matters, not to understate its relevance, we narrow the table to user and system characteristics and disregard the developer's position.

\section{Level of action}

When examining action, users' actions and system reactions have to be distinguished. Until now much attention has been paid especially to system characteristics. Most of the (historical) definitions we examined comprehend 'interactivity' as a feature of technical systems. Technical systems share various characteristics that lead, according to the respective authors, to a system being 'interactive or not interactive' or 'more or less' interactive respectively. This draws attention to a fundamental difference in popular definitions of interactivity: while many authors try to define whether a system is interactive or not (e.g. Durlak, 1987), others conceive the interactive potential of a system as a uni- or multidimensional continuum (e.g., Rogers, 1986; Heeter, 1989; Steuer, 1992; Goertz, 1995). We subscribe to the latter view and consider the interactive potential of systems as gradually classifiable. However, a bare listing of system characteristics is insufficient to describe the phenomenon of interactivity adequately. Technical systems merely offer interactive potential that has to be exploited by the user (Vorderer, 2000: 22; McMillan, 2000: 71; Wu, 1999: 254). User action and system reaction on the action level can be explained with the help of two different dimensions; the control dimension covers input by the user and the options and rules provided by the system. The transfer dimension covers all sensitive appeals and related technologies supplied by the system. Both dimensions provide information on the responsiveness (capability to react on input), which constitutes an elementary characteristic of interactive systems (cp., Durlak, 1987: 746; Ha and James, 1998: 473; Heeter, 1989: 235; Lombard and Ditton, 1997; Massey and Levy, 1999: 140; McMillan and Downes, 1998; Rogers, 1986; Straubhaar and LaRose, 1996).

Concerning the control dimension, a system's responsiveness results from three features: (1) selection options (Goertz, 1995: 486; Ha and James, 1998: 473; Heeter, 1989: 235) and (2) modification options (Coyle 
and Thorson, 2001: 67; Goertz, 1995: 487; Heeter, 1989: 235, 2000; Jensen, 1998: 201; Lombard and Snyder-Dutch, 2001). The term 'selection' not only covers the pure clicking of hyperlinks but all forms of user input that serve to select existing content. This includes text input in order to find and select certain content that applies for example to search engines. Input options are classified as 'modification' if they serve to modify the system's offerings, such as adding, deleting, and editing of text, visual, or acoustic material. Examples range from simple online polls on news websites to the modification of open systems such as Wikipedia. (3) Transfer rules finally are automatic algorithms according to which a system is capable of reacting appropriately on user selections and modifications.

The quantity and quality of selection and modification options, the transfer rules and the time horizon covered by the system finally determine its level of interactivity (Durlak, 1987: 746; Kiousis, 2002: 378; Lombard and Ditton, 1997; Steuer, 1992: 84). Within the selection dimension, the range of options may give information on the sheer quantity of selection options (e. g., the number of hyperlinks on a website) as well as on the number of different input modi (e.g., mouse click, input of words). Within the modification dimension, again the number of input options (e.g., restrictions to a certain number of characters versus entry without limitations) as well as quantity of different types of entries (text, pictures, audio, multimedia-based etc.) determines the range of options. The more natural the input and the more pristine the output may occur with the help of adequate transformation rules, the more interactive a system is. Additionally, the time horizon for a system reaction on a user selection or modification may differ from application to application. Some authors consider real-time processing a crucial criterion for interactive systems (Speed, cp., Coyle and Thorson, 2001: 67; Kiousis, 2002: 378; Lombard and Ditton, 1997; Lombard and SnyderDutch, 2001; Steuer, 1992: 84; Straubhaar and LaRose, 1996). Other authors underline that timing flexibility (i. e. a foreseeable and pre-arrangable chronology of selection and modification events) is an important advantage of interactive systems over traditional media (Kiousis, 2002: 378; McMillan, 2002a: 178; McMillan and Downes, 1998). Both perspectives are not mutually exclusive. Whereas the first attribute (speed) describes the actual reaction rate (e.g., the prompt results of a search engine or quick transfer of emails), timing flexibility aims at the system's capability for integrating reactions into the user's every day life. Numerous email programs, for example, leave it to the user to define the point of time to send an email. Auctions on eBay are also foreseeable. All hitherto mentioned characteristics refer to the control dimension and, if 
adequately implemented, serve to the usability and simplicity of the system.

Media richness (cp., e. g., Lin, 2003: 354-355) and the user's sensory activation (cp., Kiousis, 2002: 378) play a major role in the transfer dimension. Therefore some authors consider sensory complexity another central criterion to classify the level of interactivity (Durlak, 1987: 746; Kiousis, 2002: 378; Lombard and Ditton, 1997). According to this perspective, the interactive potential of a system is increased by its potential for sensory activation (aural, tactilely, olfactory, gustatory, visual). However, it can be questioned whether every single characteristic may currently give full information on the level of interactivity. Even though olfactory stimuli and gustatory stimuli have been tested before (e.g., cyber suits, odorama), they did not reach the state of mass diffusion so far. Visual and aural stimuli (even in combination), on the other hand, may indeed be regarded as indicators for the level of interactivity. Tactile stimuli already found approval in computer games such as 'Driver' where the controller is imitating agitation in case of collisions.

Thus, it has to be stated that the basic characteristics of the action level are identical both in user-user interactivity and user-system interactivity because the user addresses actions solely to the system in both cases.

\section{Level of situational evaluation}

The level of situational evaluation functions as a tie between systemdirected actions and human-centric exchange of meaning. To evaluate the situation in interactive communication, users have to rely on different parameters than in face-to-face communication, because non-verbal and partially verbal elements (facial expressions, gestures, distance between interaction partners, tone pitch, modulation etc.) that are typical for face-to-face situations are missing. To evaluate an interactive communication situation, users have to rely on their evaluation of the system and their situational sensations. We assume both that users' evaluation of the situation has a clear impact on their actions and the subsequent exchange of meaning and that there are strong interdependencies between both dimensions (system evaluation and situational sensations).

On the evaluation of the system: McMillan (2000) shows that there are clear discrepancies between the system interactivity as individually perceived and the factual system characteristics. Especially the user's evaluation of control and transfer plays an important role thereby. Evaluation of control covers all system characteristics above mentioned, such as evaluation regarding the selection options and modification options and 
evaluation of transformation rules. So far, these perception criteria have been examined separately, but not yet as a whole. Kiousis (2002), for example, considers the individually perceived system speed as a crucial criterion for the evaluation of a system's interactivity. Wu (1999) and Liu and Shrum (2002) primarily analyzed number and quantity of selection and modification options. Some examples might demonstrate that all of the system characteristics mentioned above are relevant for the evaluation of a system and resulting actions. If a user is aware that buying an article at Amazon implies transformation and implementation of any usable detail given by him as a customer into Amazon's website in order to supply personalized recommendations ("Customers who bought this book also bought ..."), he will possibly cancel his purchase because he is sensitive towards usage of personal data (evaluation of transformation rules). Utilization of computer games also depends on the user's knowledge about options provided and their prevailing use (evaluation of selection and modification options). The evaluation of the sensory complexity plays a role as well; depending on the user's experience with 'rumble'-featured joysticks, such tactile stimuli will cause irritation or a lot more fun.

On situational sensations: according to Ha und James (1998), especially playfulness and connectedness with interaction partners in cyberspace are characteristic for situational sensations. McMillan and Downes (1998) enhance this idea and talk about users developing a sense of place that leads to a feeling of a close community. 'Sense of place' as a category is closely linked to the 'presence' or 'social presence' concept (cp. Short, Williams, and Christie, 1976; Steuer, 1992; Lombard and Ditton, 1997; Lee, 2004). Lee describes presence sensations as a psychological state: (a) virtual objects (buildings, motorcars), (b) virtual social actors (user-user interactivity: virtual representation of others; user-system interactivity: virtual characters), or (c) the user's virtual representation (e. g. as an avatar in computer games) are considered as real (Lee, 2003: 44-46). From this perspective, a permanent participation in a virtual reality perceived as real may lead to an intensification of experience; more intensive than the experience of traditional media. This phenomenon is called 'immersion' (Vorderer, 1992; Schlütz, 2002: 37). Sensations of playfulness, connectedness, presence, and immersion are not limited to interactive communication situations. A suspense fiction book may for example also lead to immersion. It is assumed though that a higher level of interactivity increases these kinds of sensations.

All dimensions on the situation-evaluation level are applicable to both user-user and user-system interactivity. All characteristics should be conceived gradually again. From this perspective it seems reasonable that 
the individual evaluation of the situation depends on a further set of individual characteristics, such as experience in using interactive systems, previous knowledge, and media competence.

\section{The level of the exchange of meaning}

According to several authors the exchange of meaning between interaction partners plays a central role when examining interactivity (explicitly termed 'exchange' in Haeckel, 1998: 63; Rafaeli, 1988: 116; Rafaeli and Sudweeks, 1997; Williams, Rice, and Rogers, 1988: 115, Pavlik, 1998: 137, Straubhaar and La Rose 1996: 12; 'dialogue' in Bezjian-Avery, Calder, and Iacobucci, 1998: 23). Control and direction of communication may offer information on the disposition of power between sender and receiver. A fundamental criterion for interactive processes is the decrease of control on the part of the sender and an increase of power for the user (Bezjian-Avery, Calder, and Iacobucci, 1998: 23; McMillan, 2002b: 276; McMillan and Downes, 1998; Williams, Rice and Rogers, 1988: 115). This is allowed, on the part of the system, by numerous selection and modification options. Nevertheless, it is not necessary that sender and receiver have exactly the same level of control. Thus, control over transferred content in user-system interactivity is rather dominated by the developer, whereas proportions may appear more balanced in useruser interactivity. Closely connected to this criterion is the direction of communication. Interactive communication is foremost bi- or multilateral communication (Kiousis, 2002: 375; McMillan and Downes, 1998; Pavlik, 1998). As highlighted by several authors, this two-sidedness of the process does not necessarily imply that there is a perfect balance of power (e.g., McMillan, 2002b: 169). Even though dominance of the sender might be limited to some extent, this does still not imply equality between sender and receiver. This is why the disposition of power between communicator and addressee is comprehended as gradual by most of the authors. The more control the user gains over the communication process, the more interactive the communication becomes.

To achieve interactive communication at all, users finally have to construct meaning with the help of technically transferred symbols, which vice versa have to be decoded by their communication partners. The form of the exchange of meaning is not independent from the system's characteristics (cp. section 3.1.) and the individual evaluation of the situation. This can be derived from numerous abbreviations used in interactive communication. Acronyms such as 'CU' (see you) or 'rofl' (rolling on the floor laughing) owe their origin to limitations of systems and their users' inventiveness. Conversations via short message service should be quick and easy, abbreviations where self-evident. Some of these acro- 
nyms have their origin in online computer games where players had to communicate and play the game at the same time. Thus abbreviations helped to keep pace with the game and finally found their way to other communication services such as email.

Dimensions such as the encoding of meaning (active construction of meaning via technical means) and the decoding of meaning (reconstruction of meaning of received messages) described in Table 1 do not differ from traditional communication concepts. The exchange of meaning via written text requires, for example, an evaluation of addressees (and their language competence) by the sender and approximation to their expectations. Senders will also incorporate, consciously or unconsciously, their communication intent into the construction of meaning. On the other hand, the receiver will evaluate the sender and his intentions and reconstruct the meaning of the content individually. But still, one can expect a variation of the communication situation depending on the level of interactivity. In order to enhance communication naturalness (cp. section 2.3), interactive systems should admit a preferably intuitional encoding and decoding.

To give the impression of a real exchange of meaning, both sender and receiver have to identify an interrelatedness of messages. This means that subsequent communication sequences correspond to preceding communication sequences (Ha and James, 1998: 459; Newhagen, Cordes, and Levy, 1996: 164; Rafaeli, 1988: 111; Rafaeli and Sudweeks, 1997). Rafaeli (1988: 111) poses the highest demands of all authors to interactivity: "Interactivity is an expression of the extent that in a given series of communication exchanges, any third (or later) transmission (or message) is related to the degree to which previous exchanges referred to even earlier transmissions". This means that no exchange process is necessarily interactive from the beginning. Interactivity is granted when there is at least one interaction sequence comprising for example an inquiry, an adequate reaction by the system, or a user and a subsequent reaction of the inquirer. We do not agree with Rafaeli's claim. According to Rafaeli, an interaction process is not interactive when the third element of the sequence (subsequent reaction of the inquirer) is missing; which often applies to email conversation (inquiry - answer). Rafaeli's perspective narrows the variations of interactivity and covers only a few of numerous processes that are commonly accepted as 'interactive'. It appears more reasonable to regard the criterion of meaning exchange as gradual and to go one step back from Rafaeli's definition. We therefore consider processes interactive that admit bilateral exchange of meaning and cover at least one interaction sequence comprised of two elements (inquiry - answer). Thus email conversations without a third adequate reaction of the sender are still interactive. Here, the term 'interactive' 
seems to be close to its everyday meaning. Concerning different grades of interactivity, processes can be seen as; the more interactive, the more interdependent sequences follow each other.

\section{Connecting the levels - perspectives for further research}

As interactivity can be conceived as the result of a complex interplay between action, situational evaluation, and the exchange of meaning; connecting the three different levels described above offers the opportunity to open new research perspectives. The result of interactive media usage should mainly depend on how successful, i.e. precise the different components (user actions, system reactions, evaluation of the situation, and the exchange of meaning) work together. From our framework of analysis, at least six different connections (research perspectives) can be derived that pay attention to different sub-processes in interactive situations.

1. Connections on the level of action describe how precise a system reacts on the action of users within the dimensions of control and transfer. On the one hand, it is a question whether the system precisely reacts in the way planned by its developers. On the other hand, it might be a question whether the system does provide any possible options expected and required by the user. From this perspective, developers are able to consult error logs or usability tests and to draw conclusions on the further development of the system.

2. Connections between action and situational evaluation. One may furthermore ask whether the user's evaluation of the system corresponds to actual offered options, transformation rules and sensual complexity and whether the implemented system characteristics are suited for appropriate situational sensation. Not to forget interdependencies between the evaluation of the situation and user action. It is a debatable point whether the user is able to evaluate the system and is therefore acting adequately.

3. Connections between action and exchange of meaning. The precise correlation between user action, system reaction, and exchange of meaning also deserves attention. The question is to what extent messages delivered by the system admit the evaluation of sender, addressee, and the disposition of power. Another question might be how consistent messages can be phrased and how precise communicational intents may be encoded.

4. Connections on the level of situational evaluation. On this level, interdependences between system evaluation and situational sensations occur. It may be of interest to examine how strongly the evaluation of 
the system and the corresponding situational sensations are matching and which individual differences between different users can be assessed. This question addresses the relation of the individually perceived level of interactivity of a system to the sensation of presence or immersion.

5. Connections between situational evaluation and exchange of meaning. Misunderstandings may serve as a typical example for a failure of successfully linking the individual evaluation of the situation to the exchange of meaning. Users may be tremendously mistaken in their situational evaluation when they open an apparently harmless and funny attachment containing worms or viruses. In this case the exchange of meaning has failed; the user was not able to evaluate the communicational intent of the sender. On a more abstract level: It is an interesting question here how the individual system evaluation and situational sensations may serve to encode and decode meaning and to evaluate the distribution of power.

6. Connections on the level of the exchange of meaning. On this level one may examine how encoding and decoding correlate. This question may be posed for any kind of communication situation, although different specifications have to be expected. The above mentioned abbreviations used in interactive communications may serve as an example here: Acronyms such as 'CU' (See you!), are idiosyncratic for online communication and their meaning must be known by all interaction partners in order to transfer the message they carry.

\section{Conclusion}

"Interactivity is an underdefined concept". Rafaeli's words are found in nearly every interactivity-related paper (1988: 110). 19 years after Rafaeli's statement, we found a rather over-defined concept of interactivity, which is still missing distinctiveness, conceptual clarity, and attempts to systematize the various theoretical and empirical findings.

From our point of view, it seems important to examine different forms of interactivity and to keep an eye on the varying situations in the usage of interactive systems. Although the exchange of meaning in both useruser interactivity and user-system interactivity actually occurs (as examined in section 2.3) between human beings, there are different conditions in user-system interactivity and user-user-interactivity which lead to varying ways of utilization of interactive technologies. The proposed framework of analysis may be just a further step towards a better understanding of interactivity. On the one hand, it may serve to systematize criteria for interactivity found in the related literature by linking hitherto noncorrelated characteristics. On the other hand, all levels, dimensions, and 
characteristics of interactive communication are applicable for both useruser interactivity and user-system interactivity. However, specificity and weight of the mentioned interactivity-characteristics differ in both forms of interactivity. We therefore plead for a gradual understanding on each of the three levels of interactive communication. This basic concept is not new, as the gradual understanding of system characteristics has been introduced before by Rogers (1986) and Goertz (1995), but it currently gains importance facing an accelerated development in technology that introduces new devices on an almost daily basis. An excluding concept, differentiating interactive and non-interactive systems, is not sufficient to anticipate future developments and is therefore deficient to classify new systems and their utilization. A concept that comprehends interactivity as gradual allows a classification of future products and is able to define the user's correspondent course of action.

\section{References}

Bezjian-Avery, A., Calder, B., and Iacobucci, D. (1998). New media interactive advertising vs. traditional adverstising. Journal of Advertising Research, 38, $23-32$.

Bierig, J. and Dimmick, J. (1979). The late night radio talkshow as interpersonal communication. Journalism Quarterly, 56, 92-96.

Biocca, F. (1993). Communication research in the design of communication interfaces and systems. Journal of Communication, 43, 59-68.

Blumer, H. (1986). Symbolic interactionism: Perspective and method. Berkeley, CA: University of California Press.

Brody, E. W. (1990). Communication tomorrow: New audiences, new technologies, New Media. New York: Praeger.

Carey, J. (1989). Interactive media. In E. Barnouw (Ed.), International encyclopedia of communications (pp. 328-330). New York: Oxford University Press.

Coyle, J. R. and Thorson, E. (2001). The effects of progressive levels of interactivity and vividness in web marketing sites. Journal of Advertising, 30, 65-77.

Davies, H. and Rarick, G. (1964). Functions of editorials and letters to the editor. Journalism Quarterly, 41, 108-109.

Durlak, J. T. (1987). A typology for interactive media. In M.L. McLaughlin. (Ed.), Communication yearbook, 10 (pp.743-757). Newbury Park: Erlbaum.

Forsythe, C., Grose, E., and Ratner, J. (Eds.) (1998). Human factors and web development. Mahwah, NJ, London: Erlbaum.

Forsythe, S. A. (1950). An exploratory study of letters to the editor and their contributors. Journalism Quarterly, 14, 143-144.

Gans, H. J. (1977). Audience mail: Letters to an anchorman. Journal of Communication, 27, 86-91.

Goertz, L. (1995). Wie interaktiv sind Medien? Auf dem Weg zu einer Definition von Interaktivität. Rundfunk und Fernsehen, 43, 477-493.

Grey, D. L. and Brown, T. R. (1970). Letters to the editor: Hazy reflections and public opinion. Journalism Quarterly, 47, 450-456.

Ha, L. and James, L. E. (1998). Interactivity reexamined: A baseline analysis of early web sites. Journal of Broadcasting and Electronic Media, 42, 457-474.

Haeckel, S.H. (1998). About the nature and future of interactive marketing. Journal of Interactive Marketing, 12, 63-71. 
Heeter, C. (1989). Implications of new interactive technologies for conceptualizing communication. In J. L. Salvaggio and J. Bryant (Eds.), Media use in the information age: Emerging patterns of adoption and consumer use (pp. 217-235). Hillsdale: Earlbaum.

Heeter, C. (2000). Interactivity in the context of designed experiences. Journal of Interactive Advertising, 1. Retrieved July 27, 2006, from http://www.jiad.org/vol1/no1/ heeter/index.htm.

Höflich, J.R. (1995). Vom dispersen Publikum zu "elektronischen Gemeinschaften". Plädoyer für einen erweiterten kommunikationswissenschaftlichen Blickwinkel. Rundfunk und Fernsehen, 43, 518-537.

Horton, D. and Wohl, R. R. (1956). Mass communication and parasocial interaction: Observations on intimacy at a distance. Psychiatry, 19, 215-229.

Jäckel, M. (1995). Interaktion. Soziologische Anmerkungen zu einem Begriff. Rundfunk und Fernsehen, 43, 463-476.

Jensen, J. F. (1998). 'Interactivity'. Tracking a new concept in media and communication studies. Nordicom Review, 19, 185-204.

Katz, E., Blumler, J. G., and Gurevitch, M. (1973). Uses and gratifications research. Public Opinion Quaterly, 37, 509-523.

King, E. (1998): Redefining relationships. Interactivity between news producers and consumers. Convergence, 4, 26-32.

Kiousis, S. (2002). Interactivity: A concept explication. New Media and Society, 4, $355-383$.

Lee, K. M. (2004). Presence, explicated. Communication Theory, 14, 27-50.

Lin, C. A. (2003). An interactive communication technology adoption model. Communication Theory, 13, 345-365.

Liu, Y. and Shrum, L. J. (2002). What is interactivity and is it always such a good thing? Implications of definition, person, and situation for the influence of interactivity on advertising effectiveness. Journal of Advertising, 31, 53-64.

Lombard, M. and Ditton, T. (1997). At the heart of it all: The concept of presence. Journal of Computer Mediated Communication, 3. Retrieved May 21, 2006, from http://www.ascusc.org/jcmc/vol3/issue2/lombard.html.

Lombard, M. and Snyder-Dutch, J. (2001). Interactive advertising and presence: A framework. Journal of Interactive Advertising, 1. Retrieved July 27, 2004, from http://www.jiad.org/vol1/no2/lombard/index.htm.

Lowe, D. and Hall, W. (1999). Hypermedia and the web. An engineering approach. Chichester, New York, Weinheim, Brisbane, Singapore, Toronto: Wiley.

Maletzke, G. (1963). Psychologie der Massenkommunikation. Hamburg: Hans-BredowInstitut.

Massey, B. L. and Levy, M. R. (1999). Interactivity, online journalism, and Englishlanguage newspapers in Asia. Journalism and Masscommunication Quarterly, 76, $138-151$.

McGuire, B. and Leroy, D. J. (1977). Audience mail: Letters to the broadcaster. Journal of Communication, 27, 79-85.

McMillan, S. J. (2000). Interactivity is in the eye of the beholder: Function, perception, involvement, and attitude toward the web site. In M. A. Shaver (Ed.), Proceedings of the 2000 Conference of the American Academy of Advertising (pp. 71-78). East Lansing: Michigan State Universtiy.

McMillan, S. J. (2002a). Exploring models of interactivity from multiple research traditions: User, documents and systems. In L. A. Lievrouw, and S. Livingstone (Eds.): Handbook of new media. Social shaping and consequences of ICTs (pp.163182). London: Sage.

McMillan, S. J. (2002b). A four-part model of cyber-interactivity. New Media and Society, 4, 271-291. 
McMillan, S. J. and Downes, E. J. (1998). Interactivity: A qualitative exploration of definitions and models. Paper presented at the Annual Conference of the Association for Educators in Journalism and Mass Communication, Baltimore, MD, August 1998.

Mead, G. H. (1934). Mind, self, and society. From the standpoint of a social behaviorist. Chicago, IL: University of Chicago Press.

Newhagen, J. E., Cordes, J. W., and Levy, M. R. (1996). Nightly@NBC.Com: Audience scope and the perception of interactivity in viewer mail on the internet. Journal of Communication, 45, 164-175.

Nielsen, J. (2000). Designing web usability: The practice of simplicity. Indianapolis: New Riders Publishing.

Orians, W. (1991). Hörerbeteiligung im Radio. Eine Fallstudie zu Motivation, Erwartung und Zufriedenheit von Anrufern. München: Reinhard Fischer.

Pavlik, J. V. (1998). New media technology: Cultural and commercial perspectives. Boston: Allyn and Bacon.

Rafaeli, S. (1988). Interactivity. From new media to communication. In R. P. Hawkins, J. M. Wiemann and S. Pingree (Eds.), Advancing communication science: Merging mass and interpersonal processes (pp. 110-134). Newbury Park: Sage.

Rafaeli, S. and Sudweeks, F. (1997). Networked interactivity. Journal of Computer Mediated Communication, 2. Retrieved August 03, 2006, from http://www.ascusc. org/jcmc/vol2/issue4/rafaeli.sud-weeks.html.

Rogers, E. M. (1986). Communication technology. The new media in society. New York: Free Press.

Rubin, A. M. and Step, M. M. (2000). Impact of motivation, attraction, and parasocial interaction on talk-radio listening. Journal of Broadcasting and Electronic Media, 44: 635-654.

Rubin, A. M. (2002). The uses-and-gratifications perspective of media effects. In J. Bryant and D. Zillmann (Ed.), Media effects. Advances in theory and research. Second Edition (pp. 525-548). Hillsdale, NJ: Erlbaum.

Schlütz, D. (2002). Bildschirmspiele und ihre Faszination. München: Fischer.

Schönbach, K. (1997). Das hyperaktive Publikum - Essay über eine Illusion. Publizistik, 42, 279-286.

Schönhagen, P. (2004). Soziale Kommunikation im Internet. Zur Theorie und Systematik computervermittelter Kommunikation vor dem Hintergrund der Kommunikationsgeschichte. Bern: Peter Lang.

Schweiger, W. and Quiring, O. (2005). User-generated content on mass media web sites - just a variety of interactivity or something completely different? Paper presented to the annual conference of the International Communication Association, New York.

Short, J., Williams, E., and Christie, B. (1976). The psychology of telecommunications. London: Wiley.

Steuer, J. (1992). Defining virtual reality: Dimensions determining telepresence. Journal of Communication, 42, 73-93.

Straubhaar, J. and LaRose, R. (1996). Communications media in the information society. Belmont, CA: Wadsworth Press.

Turing, A. (1950). Computing machinery and intelligence. Mind, 59, 433-460.

Vorderer, P. (1992). Fernsehen als Handlung: Fernsehfilmrezeption aus motivationspsychologischer Sicht. Berlin: Edition Sigma.

Vorderer, P. (2000). Interactive media and beyond. In D. Zillmann and P. Vorderer (Eds.), Media entertainment. The psychology of its appeal (pp. 21-36). Mahwah, NJ, London: Earlbaum. 
Weber, M. (1984). Soziologische Grundbegriffe. Mohr Siebeck: UTB.

Williams, F., Rice, R. E., and Rogers, E. M. (1988). Research methods and the new media. New York: Free Press.

Woldt, R. (2004). Interaktives Fernsehen - große Potenzial, unklare Perspektiven. Media Perspektiven, 7, 301-309.

Wu, G. (1999). Perceived interactivity and attitude toward websites. In M. S. Roberts (Ed.), Proceedings of the American Academy of Advertising (pp. 254-262). Gainesville: University of Florida. 
Bereitgestellt von | Universitaetsbibliothek der LMU Muenchen Angemeldet | 129.187.254.47

Heruntergeladen am | 28.10.13 10:26 